\title{
Correction to: The Influence of Soil Stochastic Heterogeneity and Facility Dimensions on Stormwater Infiltration Facilities Performance
}

\author{
Andrea D'Aniello ${ }^{1} \cdot$ Luigi Cimorelli $^{1} \cdot$ Luca Cozzolino $^{2}$
}

Published online: 19 November 2019

(C) Springer Nature B.V. 2019

\section{Correction to: Water Resour Manag \\ https://doi.org/10.1007/s11269-019-02268-x}

The original version of this article unfortunately contains mistakes introduced during the publishing process. The mistakes and corrections are described in the following list, the main error lies in Table 1, page 2402.

1) The values of horizontal and vertical correlation length are inverted. Therefore, the correct values should be:

- Horizontal Correlation Length $=1.5 \mathrm{~m}$;

- Vertical Correlation Length $=5 \mathrm{~m}$.

2) Moreover, the following sentences should be changed accordingly:

- Section 3.2 Heterogeneous Scenario, page 2408, third paragraph, third line from the beginning of the paragraph. The sentence "When the bottom length is lower of about 3.3 $(B=1.5 \mathrm{~m})$ and $1.7(B=3 \mathrm{~m})$ times than the horizontal correlation length $(5 \mathrm{~m})$ of the spatial variability of the intrinsic permeability field, the distributions (Figs. 6 and 7) appear to be markedly right-skewed with a spread mostly oriented towards high values (B

The online version of the original article can be found at https://doi.org/10.1007/s11269-019-02268-x

Andrea D'Aniello

andrea.daniello@unina.it

1 Department of Civil, Architectural and Environmental Engineering, University of Naples Federico II, via Claudio 21, 80125 Naples, Italy

2 Department of Engineering, Parthenope University of Naples, Centro Direzionale di Napoli - Isola C4, 80143 Naples, Italy 
$=1.5 \mathrm{~m}$ in particular). Conversely, as the bottom length becomes higher than the horizontal correlation length of about $1.2(B=6 \mathrm{~m})$ and $2.4(B=12 \mathrm{~m})$ times, the distributions (Figs. 6 and 7) become more symmetric." should be changed with "When the bottom length is equal to the horizontal correlation length $(1.5 \mathrm{~m})$ of the spatial variability of the intrinsic permeability field, the distributions (Figs. 6 and 7) appear to be markedly right-skewed with a spread mostly oriented towards high values. Conversely, as the bottom length becomes higher than the horizontal correlation length, the distributions (Figs. 6 and 7) become more symmetric.";

- Conclusions, page 2413, fifth line from the beginning of the section. The part "...the bottom length is lower than the..." should be changed with "...the bottom length is equal to the...".

Publisher's note Springer Nature remains neutral with regard to jurisdictional claims in published maps and institutional affiliations. 